\title{
A GOVERNANÇA DA CADEIA PRODUTIVA DO LEITE: UM ESTUDO DE CASO NA REGIÃO DO COREDE RIO DA VÁRZEA - RS
}

\author{
GOVERNANCE OF MILK PRODUCTION CHAIN: \\ A CASE STUDY IN THE REGION OF COREDE RIO DA VÁRZEA - RS
}

MARIANE RUBIN DEUTSCHMANN

Universidade Federal de Santa Catarina (UFSC)

Mestranda em Administração (UFSC)

Orcid: https://orcid.org/0000-0003-3201-6819 / E-mail: marianerubin@hotmail.com

TIAGO ZARDIN PATIAS

Universidade Federal de Santa Maria (UFSM)

Doutor em Administração (UFSM)

Orcid: https://orcid.org/0000-0003-4560-6690 / E-mail: tzpatias@yahoo.com.br Av. Independência, 3751, Bairro Vista Alegre, Palmeira das Missões/RS, CEP: 98300-000

\author{
SINADIA FRITZ \\ Universidade Federal de Santa Maria (UFSM) \\ Mestranda em Agronegócios (UFSM) \\ Orcid: https://orcid.org/0000-0002-8220-5522 / E-mail: sinadiafritzz@hotmail.com
}

Submissão: 30/12/2020. Revisão: 04/05/2021. Aceite: 25/07/2021. Publicação: 28/07/2021.

DOI: http://dx.doi.org/10.22277/rgo.v14i3.5988

\begin{abstract}
RESUMO
A estrutura de governança é um dos fatores determinantes para o sucesso de uma cadeia produtiva com a capacidade de integrar, coordenar e articular ações conjuntas em prol do seu desenvolvimento. Nesse sentido, o objetivo do estudo foi caracterizar e analisar a governança e a cadeia produtiva do leite na região do Conselho Regional de Desenvolvimento Rio da Várzea. Dessa forma, foi realizada uma pesquisa descritiva, qualitativa, utilizando como instrumentos a pesquisa documental, observação direta e entrevista semiestruturada com 9 (nove) agentes da cadeia produtiva do leite da região. Em seguida, após as transcrições, procedeu-se à análise de conteúdo, identificando-se três categorias: coordenação, oportunidades e desafios. Pode-se verificar que há muitas entidades trabalhando em prol da cadeia produtiva, em que pese de forma isolada e com raros momentos de interação, constatando a existência de uma governança informal e híbrida carente de mecanismos de gestão. Sendo assim, com o envolvimento entre os agentes, em um processo coletivo, integrado, de aprendizado, crescimento e qualificação, é possível maximizar os recursos, ter uma cadeia mais consolidada e organizada, contribuindo para o seu fortalecimento, tendo uma opção de potencialização para a cadeia produtiva e a região a formalização e constituição de um Arranjo Produtivo Local (APL). Por fim, destaca-se que a cooperação entre os agentes deve ser incentivada, com foco principal nos desafios, o que proporcionará aos produtores, empresas e os municípios, desenvolvimento econômico, social e ambiental.
\end{abstract}

Palavras-chave: Governança. Cadeia Produtiva. Cadeia de Valor.

Este é um artigo publicado em acesso aberto (Open Access) sob a licença Creative Commons Attribution, que permite uso, distribuição e reprodução em qualquer meio, sem restrições desde que o trabalho original seja corretamente citado. 


\begin{abstract}
The governance structure is one of the determining factors for the success of a production chain with the ability to integrate, coordinate and articulate joint actions for its development. In this sense, the objective of the study was to characterize and analyze the governance and the milk production chain in the region of the Rio da Várzea Regional Development Council. Thus, a descriptive and qualitative research was conducted, using as instruments the documentary research, direct observation and semistructured interview with 9 (nine) agents of the milk production chain of the region. Then, after the transcriptions, we proceeded to content analysis, identifying three categories: coordination, opportunities and challenges. It can be seen that there are many entities working in favor of the production chain, despite in isolation and with rare moments of interaction, noting the existence of an informal and hybrid governance lacking management mechanisms. Thus, with the involvement between agents, in a collective, integrated process of learning, growth and qualification, it is possible to maximize resources, have a more consolidated and organized chain, contributing to its strengthening, having an option of potentialization to the production chain and the region the formalization and constitution of a Local Productive Arrangement (APL). Finally, it is emphasized that cooperation between agents should be encouraged, focusing mainly on the challenges, which will provide producers, companies and municipalities, economic, social and environmental development.
\end{abstract}

Keywords: Governance. Productive chain. Network.

\title{
1 INTRODUÇÃO
}

Projeções apontam que a atual população mundial de 7,7 bilhões, atinja 8,6 bilhões em 2030, 9,8 bilhões em 2050, e 11,2 bilhões em 2100 (UNITED NATIONS DEPARTMENT OF ECONOMIC AND SOCIAL AFFAIRS, 2017). Dado esta variável, com o crescente aumento da população, o agronegócio brasileiro tem destaque pela considerável importância na produção de alimentos e consequentemente pela sua exportação. Entre as atividades do agronegócio, a pecuária leiteira é uma das principais cadeias produtivas e o leite um dos produtos mais importantes na alimentação do ser humano, muito consumido in natura ou através de seus derivados.

O Brasil é considerado o terceiro maior produtor de leite do mundo, com volume de 33,5 milhões de toneladas, ficando atrás somente dos líderes nesse mercado: Estados Unidos e Índia. No entanto, se observar a produtividade média por animal, o Brasil despenca para 18응 lugar, indicando o quanto se pode evoluir nesse segmento (EMBRAPA, 2019). Segundo o Anuário do Leite produzido pela Embrapa (2019), a região sul tem destaque, pois produz em torno de $35,7 \%$ do volume total do leite no país, sendo Paraná e Rio Grande do Sul os estados com maior produtividade. Com isso, nota-se a importância de compreender a atual situação da cadeia produtiva do leite nessa região. Este estudo tem foco na região do Conselho Regional de Desenvolvimento da região do Rio da Várzea (COREDE-RV), composta por vinte municípios localizados na região noroeste do Rio Grande do Sul.

Uma cadeia produtiva é considerada um conjunto de ações entre os agentes de interesses que interagem do início ao fim no processo de um determinado produto, ou seja, fornecedores, distribuidores e, por fim, os consumidores (ARAÚJO, 2007). Um dos elementos essenciais quando se discute cadeias produtivas é a governança, que segundo Humphrey e Schmitz (2000), são os processos de coordenação dos agentes de um determinado sistema 
A governança da cadeia produtiva do leite:

um estudo de caso na região do Corede Rio da Várzea - RS

produtivo, em suas várias esferas de relacionamento. Portanto, na busca de oferecer condições adequadas para a cadeia produtiva do leite lidar com as mudanças do mercado, a governança se apresenta como um meio de coordenação, fruto da cooperação entre agentes econômicos que atuam em diferentes setores da economia e que incentivam e compartilham dos resultados.

Diante disto, compreender em profundidade as relações estabelecidas na cadeia produtiva do leite no COREDE-RV pode contribuir para que se tenha um aumento da sua competitividade e maiores ganhos econômicos, sociais e ambientais para todos os elos. Dessa forma, o estudo da cadeia produtiva analisa o grau de importância e as potencialidades do segmento na região, assim como avalia as estratégias e ações realizadas para garantir melhorias a determinado segmento. Dito isso, o objetivo da presente investigação é caracterizar e analisar a governança e a cadeia produtiva do leite na região do COREDE-RV.

A pesquisa contribui de forma a cooperar com as políticas públicas e privadas do setor para o fortalecimento da cadeia produtiva leiteira, através da identificação do cenário atual que se busca fornecer subsídios para a formulação de estratégias e ações de desenvolvimento setorial e regional e, consequentemente, atrair maiores investimentos na cadeia. Além disso, leva-se em consideração a importância da bovinocultura de leite para a sociedade, sabendo que, a mesma é fonte de renda de pequenos e médios produtores rurais e, que, os mesmos, contribuem na potencializando da região e no giro de capital da mesma.

Como consequência de uma das maiores crises sanitárias mundial, causada pela Covid19 e considerada pela OMS (2020) uma pandemia, previu-se uma reorganização na cadeia produtiva do leite e uma significativa redução de produtores e laticínios (EMBRAPA, 2020). Em virtude disso, diversas mudanças seriam necessárias para se manter no mercado, sendo fundamental a busca por um diferencial competitivo e o estreitamento entre as relações do elo da cadeia produtiva, que poderiam contribuir, principalmente, para a permanência do produto na sua atividade. Logo, buscou-se através dessa pesquisa responder as seguintes questões: "Como está caracterizada a governança da cadeia produtiva do leite na região do COREDE-RV? Qual a situação atual e as perspectivas da cadeia produtiva do leite no COREDERV?". Para tanto, o artigo traz um breve referencial teórico, apresentando em seguida a metodologia do trabalho, os principais resultados e discussão e no final tece algumas considerações finais.

\section{REFERENCIAL TEÓRICO}

\subsection{ASPECTOS TEÓRICOS DA CADEIA PRODUTIVA}

O conceito de cadeia surge na Escola Francesa de Economia Industrial como filière. Zylbersztajn e Neves (2000) referem ser uma série de operações que levam uma determinada mercadoria final a passar por vários processos até chegar ao consumidor. Da mesma forma, Batalha (2007) apresenta a cadeia produtiva como um conjunto de setores econômicos que articula os meios do processo de um produto, desde a sua produção até a sua comercialização. Em síntese, a cadeia produtiva é formada a partir do elo entre as relações de agentes econômicos e comerciais ao passar por um conjunto de processos, podendo ser entendida através dos três principais processos: a) o processo à montante, ou "antes da porteira", associado aos fornecedores, que ocorre antes da produção, ou seja, o fornecimento de insumos, máquinas, fertilizantes, defensivos, sementes etc.; b) o processo de produção, ou "dentro da porteira", que está diretamente ligado às atividades que envolvem a agricultura e 
pecuária, como por exemplo, a colheita ou criação de animais; e, c) o processo à jusante, ou "após a porteira", que se refere aos agentes envolvidos nas atividades de armazenamento, industrialização, embalagens e comercialização da commodity (ARAúJO, 2007).

Zylbersztajn e Neves (2000), ressaltam que há um gerenciamento entre os agentes do sistema, independentemente do nível de agregação. O autor aborda três subsistemas: as cadeias, produção, transferência e consumo. O primeiro subsistema compreende a indústria de insumos e produção agropastoril; o segundo reforça a transformação industrial, de estocagem e transporte; e o terceiro visa ao estudo das forças de mercado. Apesar de ser apresentada uma estrutura dos processos, não há um padrão e pode haver mais e diferentes elos na cadeia produtiva. Brum (2012), destaca que a articulação desses subsistemas é influenciada pela tecnologia e estratégia dos agentes que buscam maximizar lucro. Nesse aspecto, Callado (2010), complementa que, quanto maior a capacidade que o agente tem de agregar valor à cadeia, maior será sua influência no processo e nas inter-relações. Vale ressaltar que é de suma importância a organização e cooperação entre os atores envolvidos.

Com o intuito de compreender os elos da cadeia produtiva do leite, Medeiros e Brum (2016), referem quatro categorias nesse processo: o primeiro são os fornecedores, que fornecem insumos, máquinas e equipamentos aos produtores, podendo também abranger as instituições de ensino e fomento e a assistência técnica; os produtores rurais; o segundo elo, em que ocorre o sistema de produção principal, considerado como especializado ou não especializado; o terceiro é a indústria, muito importante, já que ela coleta do produtor e distribui para o quarto e último elo, que são os varejistas, os supermercados, as cooperativas, as padarias, que entregam o produto final ao consumidor. De acordo com Reis e Costa Neto (2018), uma gestão eficiente desses elos pode contribuir para a agregação de valor aos produtos e aumento da produção e receita de todos os envolvidos, garantindo o sucesso da cadeia.

Kelm, Sausen e Kelm (2015), afirmam que a cadeia produtiva é muito mais ampla que somente processos operacionais, pois compreendem, também, as atividades de apoio, como a gestão de conhecimento e informação, oferecidas, mesmo que indiretamente, pelas universidades e/ou instituições públicas e privadas através de treinamentos, pesquisas e eventos, que contribuem com os agentes de interesse.

$\mathrm{Na}$ década de 1990 a cadeia produtiva do leite no Brasil sofreu grandes transformações. Como cita Breitenbach e Souza (2011), devido à abertura do mercado ao comércio internacional, a consolidação do MERCOSUL, a desregulamentação do setor e a implantação do Plano Real, houve um aumento significativo na demanda maior que a oferta e alteração da estrutura de mercado de monopsônio para oligopsônio, principalmente no sul do Brasil. Além disso, Canziani (2003), aponta, que o desenvolvimento do leite UHT (pasteurizado), armazenado em embalagens, contribuiu para o aumento do consumo, uma vez que os produtores conseguiam expandir a comercialização em diversas regiões com maior validade e baixa perecibilidade.

Dessa forma, houve grande incentivo para a produção do leite, aprimorando a cadeia produtiva leiteira (VIANA; RINALDI, 2010). Para os autores, essas mudanças influenciaram na reestruturação de toda a cadeia e do elo da produção, o qual teve que adaptar seus custos de produção ao novo mercado emergente. As modificações contribuíram, ainda, para uma reestruturação da cadeia e para o incremento de novas tecnologias no setor, tendo em vista que foi possível investir mais em pesquisa e importar tecnologias que foram desenvolvidas em outros países. Com as referidas transformações, o governo diminuiu sua interferência no setor leiteiro e a competitividade aumentou no mercado, reforçando a inserção de novas 
A governança da cadeia produtiva do leite:

um estudo de caso na região do Corede Rio da Várzea - RS

tecnologias, investimento em pesquisas e especialização dos produtores de leite a fim de entregar um produto de maior qualidade ao consumidor final.

No entendimento de Canziani (2003), há duas características de produtores de leite: de um lado, os produtores especializados, com técnicas e inovações do elo anterior que, geralmente, tem por atividade principal a produção de leite; do outro, os produtores não especializados, que atuam de maneira artesanal, do qual grande parte da produção vai para o consumo próprio, tratando-se também como uma atividade de subsistência. Para estes não especializados há que se ter políticas públicas como apoio para manutenção, visando especializar-se no futuro (KISCHNER et al., 2019).

Nesse contexto, segundo Viana e Rinaldi (2010), fatores internos e externos influenciam no desempenho da produção leiteira. Os fatores internos estão ligados diretamente ao produtor, pela sua capacidade de investimentos em ordenha mecânica e armazenamento do leite em tanques de expansão, assim como a genética do rebanho e a alimentação dos mesmos são de extrema importância. No que se refere aos fatores externos, dizem respeito aos aspectos institucionais da cadeia, como a assistência técnica que auxilia o produtor em uma maior eficiência no processo de produção, como também à própria manutenção do acesso direto ou indireto às propriedades. Tais questões são importantes para a coleta do leite e para a entrega de insumos nas propriedades rurais. Portanto, o produtor de leite é o elo crucial que fornece o insumo às indústrias onde ocorrem o processamento e transformação do produto.

A indústria tem grande importância na cadeia, visto que nele ocorre o processo de transformação do leite in natura no produto final a ser consumido, como o leite UHT, o leite em pó, pasteurizado e seus derivados (KELM, SAUSEN; KELM, 2015). É com a industrialização que ocorre a agregação de valor, a busca por estratégias e a tomada de decisão mais assertiva para conquistar o mercado e os consumidores.

Para Viana e Ferras (2007), as vantagens da cadeia produtiva são: a minimização de custos, aumento na competitividade pelos preços, maior nível de qualidade dos produtos, além da diferenciação e agregação de valor. Dessa forma, as empresas buscam estratégias para obter vantagens competitivas diante da concorrência e agregar valor ao seu produto. Como consequência, Fensterseifer e Vieira (2002), destacam que é possível aumentar a produtividade, desenvolver novos produtos, entrar em novos mercados e, através de parcerias com os fornecedores, criar alianças estratégicas e institutos de pesquisas. Além disso, os autores ressaltam a importância em investir na eficiência, incorporando novas tecnologias.

Para Zylbersztajn, Neves e Caleman (2015), os consumidores são agentes de transformação na agricultura, pois criam as demandas e necessidades, exigindo das empresas as inovações tecnológicas e organizacionais. Transferindo para o enfoque da cadeia produtiva leiteira, isso não é diferente, pois são eles que recebem e consomem o produto final e avaliam conforme seu nível de satisfação e agregação de valor. No entanto, este não é um processo simples, exigindo muito empenho de todos os elos da cadeia, em especial da governança.

\subsection{ASPECTOS TEÓRICOS DA GOVERNANÇA}

Fator determinante para o sucesso de uma cadeia produtiva é a sua estrutura de governança. Segundo Justen e Souza (2017), a governança refere-se as formas pelas quais os indivíduos e instituições (públicas ou privadas) coordenam suas atividades e problemas em comum, alinhando interesses e ações conjuntas, sendo assim, a governança corresponde a 
relacionamentos formas e informais. Humphrey e Schmitz (2000), utilizam o termo governança para descrever os processos de coordenação dos agentes de um determinado sistema produtivo, em suas várias esferas de relacionamento, ou seja, entre os setores públicos e privados a nível local, regional ou global, conforme exposto no Quadro 1.

Quadro 1 - Categorias de ações público-privadas e níveis de governança local-global

\begin{tabular}{|l|l|l|}
\hline Governança privada & \multicolumn{1}{|c|}{ Nível local } & \multicolumn{1}{c|}{ Nível global } \\
\hline Clusters com empresa-líder. & $\begin{array}{l}\text { Cadeia global conduzida pelo comprador. } \\
\text { Cadeia global conduzida pelo produtor. }\end{array}$ \\
\hline Governança pública & $\begin{array}{l}\text { Agências governamentais locais e } \\
\text { regionais. }\end{array}$ & $\begin{array}{l}\text { Regras internacionais de comércio. } \\
\text { Regras nacionais e supranacionais com } \\
\text { padrões globais de fornecimento. }\end{array}$ \\
\hline $\begin{array}{l}\text { Governança público- } \\
\text { privada }\end{array}$ & $\begin{array}{l}\text { Redes de políticas regionais e } \\
\text { locais. }\end{array}$ & $\begin{array}{l}\text { Padrões internacionais. } \\
\text { Campanhas de ONGs internacionais. }\end{array}$ \\
\hline
\end{tabular}

Fonte: adaptado de Humphrey e Schmitz (2000, p. 5-6).

Essas formas de governança exercem papel importante para melhorar a competitividade dos produtores da cadeia produtiva. No caso de governança local exercida pelo setor público, as ações podem ser a criação e a manutenção de estruturas voltadas para o desenvolvimento dos produtores locais. Por outro lado, a governança local privada destaca o papel das associações de classe, dos sindicatos, das agências de desenvolvimento privadas, entre outras, que atuam como catalisadores do processo de desenvolvimento local (SUZIGAN; GARCIA; FURTADO, 2007).

Em estudo realizado sobre os três principais níveis de impacto das funcionalidades das cadeias de valor globais (GVC), apresenta-se no Quadro 2, um quadro organizado interligando os níveis entre em si e fazendo uma análise da governança e dos resultados de desempenho. Este quadro integrativo procura destacar tanto as questões específicas de comercialização, quanto as relações, não só as variáveis de nível da governança, mas também, crucialmente, as influências micro e macro que moldam as organizações e os resultados de desempenho. Saber quais são os construtos e dimensões que estão relacionados ao desempenho organizacional é um desafio constante (DIAS; DE TONI, 2018).

No nível macro, os estudos abordam os impactos da cadeia no macroambiente em que operam e investigam as relações entre a cadeia e o seu ambiente incluindo a composição cultural, institucional, geográfica e econômica dos locais de origem e de acolhimento. Já em relação ao nível micro, os autores encontraram estudos sobre o comportamento dos decisores e a forma como o conhecimento é trocado e processado, assim como são geridos os riscos de confiabilidade e como novas capacidades são desenvolvidas e as defasadas descartadas. Portanto, em relação à governança e os resultados do desempenho no nível de cadeia global, identifica-se com a atualização, desempenho e estabilidade seis grandes elementos críticos da governança estrutural e estratégica: controle, localização, estrutura da rede, aprendizagem, impacto da empresa líder e orquestração da cadeia de valor global. Mudanças assim, evoluem num ciclo constante e de reforço mútuo (KANO; TSANG; YEUNG, 2020). 
A governança da cadeia produtiva do leite:

um estudo de caso na região do Corede Rio da Várzea - RS

Quadro 2 - Estrutura institucional comparativa de governança.

\section{Influências no nível macro}

Características culturais, institucionais, geográficas, econômicas / dinâmicas dos locais de residência / acolhimento

- Qualidade e custo dos insumos de produção, nível de especialização do trabalho

- Ambiente tecnológico, regime de proteção de Indicação de Procedência

- Qualidade institucional, estabilidade política

- Desenvolvimento econômico, crescimento / declínio

- Normas e sistemas de valor

Governança Estrutural

\section{Controle}

- Fazer, comprar ou tomar decisões híbridas para cada atividade da cadeia de valor

2. Localização: mapeamento GVC

- Escolha do local para atividades discretas

- Governança regional versus governança global - Mercados emergentes versus desenvolvidos - Clusters e ligações locais

\section{Estrutura de rede}

- Relações de poder / hierarquia / grau de coordenação

- centralidade e densidade

- Heterogeneidade de ligação

- Abertura

- Imersão

\section{Governanca Estratégica}

4. Aprendizado

- Aquisição, criação e difusão de conhecimento

- Inovação e capacidade de absorção

- Captura e atualização

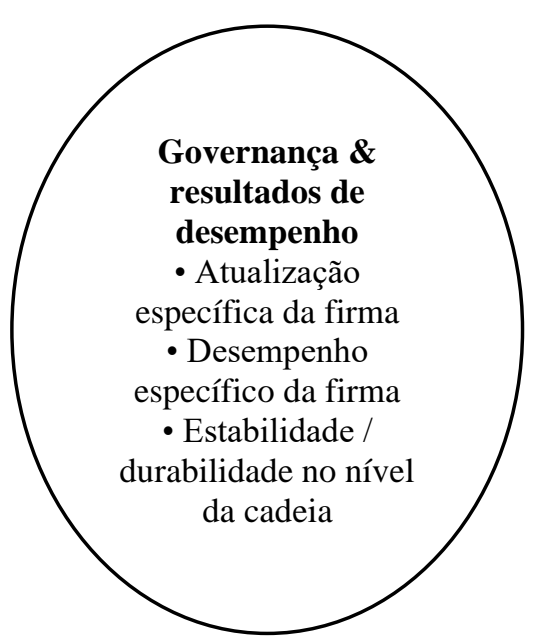

\section{Impacto da empresa} líder

- Tamanho / idade / propriedade

- Localização / setor industrial

- Estratégia

- Capacidades

\section{Orquestração GVC}

- Opções contratuais específicas para gerenciar a GVC

- Orientação empreendedora

- Mecanismos sociais / governança relacional - Distribuição de valor

\section{4}

Influências de nível micro

Pressupostos comportamentais dos tomadores de decisão nas empresas líderes e unidades periféricas:

- Racionalidade limitada e confiabilidade limitada

- Recursos cognitivos

- Recursos gerenciais, etc.

Fonte: adaptado de Kano, Tsang e Yeung (2020, p. 8, tradução nossa).

Dessa forma, a governança existente dentro das cadeias produtivas configura-se como um instrumento para melhorar a interação e as relações entre os atores e, assim, impulsionálos para o desenvolvimento local sustentável. Para analisar o processo de governança da cadeia produtiva do leite no COREDE-RV, constituiu-se um método de pesquisa condizente com o objeto de estudo, descrito a seguir. 


\section{PROCEDIMENTOS METODOLÓGICOS}

Nesta seção descreve-se, em linhas gerais, o método e as técnicas de pesquisa utilizadas nesta investigação. A intenção desta pesquisa foi desenvolver um estudo com abordagem predominantemente qualitativa, em profundidade e contextualista do processo (PETTIGREW, 1985). A primeira fase consistiu em pesquisa documental e observação direta junto as entidades envolvidas, com busca de atas, reportagens em jornais e sites sobre a cadeia produtiva do leite no COREDE-RV localizado na região norte do Estado do Rio Grande do Sul (RS) - Brasil. Destaca-se que esta é uma das microrregiões do Sul do Brasil especializada na produção de leite (TELLES et al., 2020). A parceria da Emater/Ascar que disponibilizou os dados de sua pesquisa realizada junto aos produtores foi fundamental para a qualificação da pesquisa. A segunda fase foi constituída de entrevistas semiestruturadas com os principais agentes da governança da cadeia produtiva.

Referente aos seus objetivos, o estudo é caracterizado como descritivo, pois apresenta um relato detalhado de um fenômeno social, ilustrando a complexidade da situação e dos aspectos nele envolvidos. A estratégia também é interpretativa, pois pretende "encontrar padrões nos dados e desenvolver categorias conceituais que possibilitem ilustrar, confirmar ou opor-se a suposições teóricas" (GODOY, 2010, p. 124).

A partir do objetivo da pesquisa, definiu-se como a unidade de análise, a cadeia produtiva do leite do COREDE-RV. Ressalta-se que os COREDES existentes no Rio Grande do Sul começaram a ser organizados a partir de 1991, sendo criados oficialmente pela Lei 10.283, de 17 de outubro de 1994, com o objetivo de promover o desenvolvimento regional harmônico e sustentável. São compostos por diversos tipos de instituições dos setores empresarial, sindical, associativo e universitário, além da representação política (vereadores, prefeitos e deputados) (GONZÁLEZ, 2008). A região que congrega o COREDE-RV compõe-se por 20 municípios, tendo uma população de 135.446 habitantes, em uma área total de 4.907,8 $\mathrm{km}^{2}$ (FUNDAÇÃO DE ECONOMIA E ESTATÍSTICA SIEGFRIED EMANUEL HEUSER, 2017).

$\mathrm{Na}$ segunda fase da pesquisa foram realizadas 9 (nove) entrevistas semiestruturadas, fluidas e não rígidas, com os informantes-chave da governança da cadeia produtiva do leite do COREDE-RV. Estes informantes-chave foram os selecionados pela sua qualificação, diversidade, tempo de participação e representatividade junto a cadeia produtiva. São pessoas que fazem parte das entidades que trabalham diretamente com a cadeia produtiva do leite na região, que são: Emater/Ascar, Entidades de Ensino e Pesquisa, Sindicatos, Indústrias, Cooperativas e Secretarias Municipais de Agricultura.

Buscando validar o roteiro de entrevista, um pré-teste foi aplicado, no mês de junho de 2019, com um dos atores principais da cadeia produtiva, sendo realizados pequenos ajustes para melhorar as orientações aos entrevistados. As entrevistas foram realizadas face a face, nos meses de julho e agosto de 2019. As entrevistas foram gravadas em áudio a partir do consentimento dos entrevistados, sendo que o tempo médio de duração destas entrevistas foi de uma hora, realizada uma única vez. As entrevistas abordaram os seguintes temas: compreensão de APL, pontos fortes, fracos, oportunidades e ameaças para a cadeia produtiva do leite na região do COREDE_RV, cooperação, associativismo, planejamento e gestão.

A análise das evidências qualitativas utilizou-se da técnica de análise de conteúdo, que segundo Bardin (2009, p. 40), é "um conjunto de técnicas de análise das comunicações que utiliza procedimentos sistemáticos e objetivos de descrição do conteúdo das mensagens". Complementando o conceito, a autora diz que "a intenção da análise de conteúdo é a inferência de conhecimentos relativos às condições de produção (ou, eventualmente, de recepção), inferência esta que recorre a indicadores (quantitativos ou não)". 
A governança da cadeia produtiva do leite:

um estudo de caso na região do Corede Rio da Várzea - RS

Para Bardin (2009), existem três fases na análise de conteúdo organizadas em torno de três polos cronológicos: a) a pré-análise; b) a exploração do material; c) o tratamento dos resultados, a inferência e a interpretação. Segundo esta autora, a fase de pré-análise é a de organização, com o objetivo de tornar operacionais e sistematizar as ideias iniciais. A exploração do material consiste na codificação, que é a transformação sistemática dos dados brutos com posterior agregação em unidades que serão enumeradas e categorizadas.

Ressalta-se que a categorização é um processo de agrupamento por sentido e, conforme Laville e Dionne (1999), pode acontecer de três formas: aberto, fechado e misto. Na presente investigação optou-se pelo modelo aberto, ou seja, as categorias tomaram forma no decorrer do processo de análise. Portanto, a partir do desmembramento de todo o material coletado, foi possível reagrupá-los em categorias emergentes, fruto de leitura atenta, buscando a compreensão e descoberta. A fase final foi o tratamento dos dados, a inferência e a interpretação.

\section{RESULTADOS E DISCUSSÕES}

Os resultados da análise dos documentos, da observação direta e das entrevistas são relatados nesta seção, de acordo com as categorias emergentes resultantes das entrevistas: coordenação, oportunidades e desafios. Além da análise de documentos, levou-se em conta as entrevistas realizadas, assim como uma discussão teórico prática para substanciar esta seção. Inicialmente, com base nos dados disponibilizados pela Emater/Ascar, destaca-se alguns números da produção de leite da região.

\subsection{DADOS DA PRODUÇÃO DE LEITE DO COREDE-RV}

A tabela 1 apresenta a quantidade de produtores de leite por município em relação ao número total de produtores rurais.

Tabela 1 - Quantidade de produtores rurais $\mathrm{x}$ produtores de leite

\begin{tabular}{l|c|c|c}
\hline \multicolumn{1}{c|}{ Municípios } & $\begin{array}{c}\text { Total de produtores } \\
\text { rurais no município }\end{array}$ & $\begin{array}{c}\text { Total de produtores de } \\
\text { leite no município }\end{array}$ & $\begin{array}{c}\text { Porcentagem de } \\
\text { produtores de leite }\end{array}$ \\
\hline Lajeado do Bugre & 546 & 379 & $69,41 \%$ \\
Engenho Velho & 110 & 67 & $60,91 \%$ \\
Nova Boa Vista & 374 & 214 & $57,22 \%$ \\
Rondinha & 947 & 496 & $52,38 \%$ \\
Chapada & 1.175 & 593 & $50,47 \%$ \\
Cerro Grande & 380 & 191 & $50,26 \%$ \\
Sarandi & 739 & 362 & $48,99 \%$ \\
Constantina & 834 & 396 & $47,48 \%$ \\
Jaboticaba & 811 & 385 & $47,47 \%$ \\
Três Palmeiras & 711 & 336 & $47,26 \%$ \\
Barra Funda & 258 & 112 & $43,41 \%$ \\
Liberato Salzano & 1.178 & 458 & $38,88 \%$ \\
Boa Vista das Missões & 311 & 111 & $35,69 \%$ \\
Ronda Alta & 778 & 254 & $32,65 \%$ \\
Novo Xingu & 470 & 98 & $20,85 \%$ \\
São Pedro das Missões & 373 & 67 & $17,96 \%$ \\
Palmeira das Missões & 1.624 & 278 & $17,12 \%$ \\
São José das Missões & 749 & 124 & $16,56 \%$ \\
Novo Barreiro & 713 & 110 & $15,43 \%$ \\
Sagrada Família & 525 & 38 & $7,24 \%$ \\
\hline Total & 13.606 & 5.069 & -- \\
\hline Média & 680 & 253,45 & $38,88 \%$ \\
\hline Fonte: & & \\
\hline
\end{tabular}

Fonte: dados referentes a 2019 disponibilizados pela Emater/Ascar. 
Como já mencionado, o COREDE-RV é composto de 20 municípios que se encontram em uma importante área produtiva de leite do Rio Grande do Sul. A seguir, apresenta-se alguns dados que auxiliam no entendimento deste contexto.

Em relação ao número de produtores de leite por município, percebe-se que o município de Lajeado do Bugre possui $69,41 \%$ de seus produtores rurais envolvidos com a produção de leite. Ao passo que Sagrada Família somente $7,24 \%$ nesta atividade. A maior quantidade em termos absolutos de produtores está em Chapada com 593 produtores de leite. A média da região é $38,88 \%$ dos produtores rurais estarem atuando com a produção de leite. A seguir apresenta-se a Tabela 2 com os dados sobre a produtividade por município.

Tabela 2 - Vacas leiteiras $\mathrm{x}$ produtividade

\begin{tabular}{l|c|c|c}
\hline \multicolumn{1}{c|}{ Município } & $\begin{array}{c}\text { Número total de vacas } \\
\text { leiteiras no município }\end{array}$ & $\begin{array}{c}\text { Volume total de leite } \\
\text { (litros/ano) produzido } \\
\text { anualmente no município }\end{array}$ & $\begin{array}{c}\text { Média por } \\
\text { vaca/dia }\end{array}$ \\
\hline Rondinha & 7.200 & 38.521 .000 & 14,66 \\
\hline Chapada & 6.500 & 32.851 .334 & 13,85 \\
\hline Constantina & 4.817 & 22.945 .000 & 13,05 \\
\hline Ronda Alta & 3.199 & 17.629 .200 & 15,10 \\
\hline Três Palmeiras & 3.833 & 14.423 .297 & 10,31 \\
\hline Sarandi & 3.931 & 14.192 .800 & 9,89 \\
\hline Nova Boa Vista & 2.186 & 13.987 .844 & 17,53 \\
\hline Liberato Salzano & 2.631 & 9.629 .914 & 10,03 \\
\hline Novo Xingu & 2.024 & 8.685 .716 & 11,76 \\
\hline Jaboticaba & 3.709 & 8.440 .415 & 6,23 \\
\hline Palmeira das Missões & 3.917 & 7.642 .779 & 5,35 \\
\hline Boa Vista das Missões & 1.276 & 7.491 .152 & 16,08 \\
\hline Barra Funda & 1.609 & 6.776 .000 & 11,54 \\
\hline Novo Barreiro & 1.127 & 5.816 .560 & 14,14 \\
\hline Cerro Grande & 1.450 & 4.650 .000 & 8,79 \\
\hline São José das Missões & 1.518 & 3.861 .120 & 6,97 \\
\hline Engenho Velho & 690 & 3.077 .685 & 12,22 \\
\hline Sagrada Família & 844 & 2.995 .000 & 9,72 \\
\hline Lajeado do Bugre & 1.117 & 2.331 .075 & 10,10 \\
\hline São Pedro das Missões & 577 & 2.128 .000 & 11,54 \\
\hline Total & 54.155 & 228.075 .891 & 11,54 \\
\hline Média & 2.708 & $11.403 .794,55$ & \\
\hline Fonte: dados referentes & & & \\
\hline
\end{tabular}

Fonte: dados referentes a 2019 disponibilizados pela Emater/Ascar.

Na Tabela 2 é possível verificar que o município de Rondinha é o que possui o maior rebanho de vacas leiteiras e consequentemente o maior volume de produção. No entanto, ao analisar a produtividade por vaca/dia, percebe-se que o município de Nova Boa Vista é o mais eficiente, com uma média de 17,53 litros de leite/vaca/dia. Aqui percebe-se claramente as diferenças entre os municípios, por exemplo, Palmeira das Missões com 5,35 litros de leite/vaca/dia. As possibilidades de aumento de produtividade são nítidas, havendo a necessidade de aprofundar o diagnóstico e utilizar as técnicas adequadas para melhoria nos índices e uma coordenação entre os principais atores, objeto de análise da próxima seção. Ainda assim, tem-se a importância da Tabela 3, na qual, apresenta-se as empresas que captam leite na região. 
A governança da cadeia produtiva do leite:

um estudo de caso na região do Corede Rio da Várzea - RS

Tabela 3 - Empresas que captam leite na região do COREDE Rio da Várzea - RS

\begin{tabular}{|c|c|c|}
\hline Empresas & $\begin{array}{l}\text { Número de município com entrega } \\
\text { na empresa }\end{array}$ & $\begin{array}{c}\text { Representatividade na região } \\
\text { COREDE-RV }\end{array}$ \\
\hline Deale Laticínios & 18 & $11,6 \%$ \\
\hline Laticínios Frizzo & 16 & $10,3 \%$ \\
\hline Friolack & 15 & $9,7 \%$ \\
\hline Italac & 13 & $8,4 \%$ \\
\hline Tirol & 13 & $8,4 \%$ \\
\hline COOPAC & 9 & $5,8 \%$ \\
\hline Nestle & 8 & $5,2 \%$ \\
\hline Cotrisal & 7 & $4,5 \%$ \\
\hline Stefanello & 7 & $4,5 \%$ \\
\hline CCGL & 6 & $3,9 \%$ \\
\hline Mandaká Alimentos & 6 & $3,9 \%$ \\
\hline Laticínios Alto Uruguai & 4 & $2,6 \%$ \\
\hline Lactalis & 4 & $2,6 \%$ \\
\hline Laticinios Seberi & 4 & $2,6 \%$ \\
\hline ZDA Alimentos & 3 & $1,9 \%$ \\
\hline COOPERLAT & 2 & $1,3 \%$ \\
\hline Lamuca & 2 & $1,3 \%$ \\
\hline Latvida & 2 & $1,3 \%$ \\
\hline Piracanjuba & 2 & $1,3 \%$ \\
\hline Outros & 12 & $9,0 \%$ \\
\hline Total & 155 & $100 \%$ \\
\hline
\end{tabular}

Fonte: dados referentes a 2019 disponibilizados pela Emater/Ascar.

No que diz respeito as empresas que captam leite na região, pode-se constatar que há 32 empresas. A Deale Laticínios lidera a coleta com a presença em 18 municípios dos 20 abrangentes da região do COREDE-RV. Além disso, a Deale juntamente com a Laticínios Frizzo, Friolack, Italac e Tirol, representam $48,4 \%$ das empresas que captam leite, ou seja, aproximadamente metade da captação da região concentra-se nestas empresas. Quanto aos outros, foram citadas somente por um município empresas como: Aurora, Bela Vista, COOPER A1, Estrela, Fochezatto, Gandin Milk, Goiasminas, LactVida, Laticínios Pinhalense, Laticínio Sarandi, Piran e Lácteos Boa vista. O fato de a indústria ser um ator fundamental quando se trata de governança, esta informação é relevante para uma futura articulação.

\subsection{COORDENAÇÃO}

Uma das categorias emergentes das entrevistas e dos documentos analisados foi a coordenação, que segundo o quadro teórico é um fator determinante para o sucesso de uma cadeia produtiva (ZYLBERSZTAJN, 2000; BATALHA, 2007; CALLADO, 2010). Percebe-se que no COREDE-RV há uma organização coletiva voltada para produção do leite, mas esta não envolve todos os municípios do COREDE-RV, nem mesmo é organizada formalmente. Se identificou uma governança informal e híbrida, do tipo público privada (HUMPHREY; SCHMITZ, 2000). A mesma é estabelecida por diversas entidades de caráter público e privado que se reúnem esporadicamente em prol de algum objetivo, por exemplo, a realização de um evento ou até 
mesmo para buscar recursos públicos, como a consulta popular. Percebe-se também a existência de uma variedade de ações desarticuladas, que poderiam ser otimizadas, caso houvesse uma governança formal e com planejamento, estrutura de poder clara, com centralidade e densidade (KANO; TSANG; YEUNG, 2020).

Os entrevistados indicaram haver carência de uma organização coletiva estruturada. Hoje está totalmente focada em ações pontuais e restritas. Há que se estabelecer um grau de diálogo maior, sob pena de não havendo uma ligação entre os elos, a cadeia produtiva vir a fracassar. Portanto, a importância de agentes conscientes de sua parte na cadeia produtiva do leite, seja a empresa que transporta, a indústria, a agroindústria, os técnicos, as instituições de ensino, a secretaria de agricultura, os técnicos que dão assistência e acompanhamento, as empresas de vendas de insumos e equipamentos, os laticínios e o próprio COREDE-RV. São responsáveis diretos para o sucesso da cadeia e, consequentemente, do produtor. As entrevistas apontam que há empresas consolidadas, que tem produtores fidedignos crescendo, enquanto tem outros que infelizmente sucumbem. Isto demonstra que é possível desenvolver ações que resultam em melhores resultados, cabendo a governança da cadeia articular, ou como citam Kano, Tsang e Yeung (2020), fazer a orquestração, para que todos os agentes sejam beneficiados.

Um fato recente e que pode ter reflexo sobre a coordenação, está a retomada industrial da unidade de processamento de leite da Nestlé em Palmeira das Missões, fechada em 2019. Um grupo de oito empresas ligadas ao setor de industrialização de leite, formaram um consórcio de laticínios, denominado WHEY POWDER Indústria de Alimentos Lácteos do Brasil Ltda, sendo sete empresas da região Norte do Rio Grande do Sul e uma da Serra gaúcha. Integram o grupo comprador a Friolack de Chapada, Mandaka de Nova Boa Vista, Doceoli de Santo Cristo, Frizzo de Planalto, São Luís de Marau, Kiformaggio de Nonoai, Paladar de Guaporé e Stefanello de Seberi. Documentos apontam que esta será uma das maiores e mais modernas fábricas de secagem de soro de leite do Brasil, além de outros produtos que também serão produzidos na unidade.

A articulação de todos os elos da cadeia produtiva é fundamental, tanto a montante (antes da porteira), o processo de produção (dentro da porteira) e a jusante (após a porteira) (ARAÚJO, 2007; BATALHA, 2007). Por isso, uma governança efetiva que assuma a coordenação regional poderá potencializar as oportunidades e trabalhar nos desafios, os quais são categorias emergentes que são tratadas nas seções seguintes.

\subsection{OPORTUNIDADES}

A categoria emergente oportunidade, agrupou os aspectos inerentes a ela, em especial aquilo que há de positivo na região. Uma oportunidade que muito favorece a região na produção leiteira é o tipo de estrutura de mercado, neste caso oligopsônio concorrencial (BREITENBACH; SOUZA, 2011), resultando em uma diversidade de empresas (32 laticínios como citado anteriormente) no setor de laticínios em cidades próximas, ou mesmo, situadas dentro da região do COREDE-RV, que captam o leite do produtor dentro do prazo necessário, essencial a característica singular perecível do produto. Com resultado de índices baixos de perda nessa etapa.

Os entrevistados apontam que o clima e características favoráveis, associados a esta região, seja quanto à manejo e amplitude de cultivos, são fatores que favorecem a produção de leite, de modo que torna possível, mediante organização, a oferta de alimentos de qualidade como pastagem ou ensilados durante o ano todo. Oportunizando assim, visto deste 
A governança da cadeia produtiva do leite:

um estudo de caso na região do Corede Rio da Várzea - RS

aspecto, uma produção contínua, mantendo todos os elos da cadeia em permanente produtividade.

Também como oportunidade está a abertura comercial para exportação do leite, que aumentaria o mercado de atuação. Recentemente o Rio Grande do Sul se destacou com seis estabelecimentos habilitados para a exportação de produtos lácteos para a China, oportunizando o fomento da cadeia produtiva do leite (MAPA, 2019). Documentos analisados indicam que a exportação do ponto de vista fiscal tem o benefício constitucional da imunidade em todos os tributos, sendo que nesse aspecto haveria a vantagem para as agroindústrias mesmo as tributadas pelo Simples Nacional, LC 123 de 2006 - de não incidir os tributos IRPJ Imposto de Renda Pessoa Jurídica e a CSLL - Contribuição Social sobre o Lucro Líquido, possibilitando assim mais rentabilidade. No entanto, como no mercado interno ainda a demanda é maior que a oferta, há um desestímulo para a exportação.

A inferência e interpretação dos conteúdos permitiu identificar que outra oportunidade para a produção leiteira é a agregação de valor do leite na transformação e na utilização de um subproduto advindo do soro do queijo. A ligação dos elos entre a produção de grãos pode contribuir para ambas as cadeias produtivas. Uma vez que, o incentivo a agroindústria e a fabricação de ração na região fortaleceria a agricultura e a pecuária, contribuindo ainda mais para a região com aumento do Valor Adicionado gerado e consequentemente, maior retorno do IPM - Índice de Participação do Município em retorno financeiro do Estado.

Da mesma forma, oportunidade está também no aprimoramento da gestão das propriedades rurais, principalmente os familiares, com olhar a conhecer seus custos, margens, fluxo de caixa, entre outros tantos necessários à análise de desempenho e gestão apropriada dos recursos nas propriedades rurais. Assessoramento que possibilite um gerenciamento autossustentável e lucrativo, pois ao contrário das grandes propriedades rurais, que dispõem de assessoramento privado de profissionais de áreas como Agronomia, Veterinária, Zootecnia, Engenharia de Alimentos e Administração, a pequena propriedade não apresenta lastro financeiro para bancar o serviço desses profissionais e, assim, impulsionar o lucro por meio de assessoria qualificada. Neste aspecto, deve-se destacar o que Kelm, Sausen e Kelm (2015) dizem da necessidade de que as instituições de apoio, como Universidades, SENAR, Emater entre outras, assumam este papel central de assessoramento. São as influências de nível micro que afetam o desempenho de toda a cadeia de valor (KANO; TSANG; YEUNG, 2020).

\subsection{DESAFIOS}

A terceira categoria emergente são os desafios. Os entrevistados destacaram inúmeros desafios para os elos da cadeia produtiva e consequentemente a governança. O principal é a necessidade de os produtores qualificarem suas ações, principalmente em relação a produção de leite e a sua forma de trabalho, que, muitas vezes, não possui processos automatizados ou não dispõe de recursos, tecnologias ou estruturas para atender o que é exigido, tanto pelas leis ambientais como pelas normativas. Canziani (2003), já destacava que há duas categorias de produtores, os especializados e não especializados, sendo que estes últimos, sem o apoio governamental, tendem a desaparecer (KISCHNER et al., 2019).

O produtor encontra dificuldades para a realização de atividades básicas em sua propriedade, desde o manejo e adubação adequada das pastagens, a alimentação balanceada na dieta dos bovinos de leite, até mesmo o acesso das estradas para a coleta do leite. E, para que consigam permanecer no ramo é preciso qualificar seu planejamento e organização da 
propriedade, com mais informações, conhecimento e assistência técnica especializada. Pois o investimento nos tratos culturais do bem-estar animal, na genética, nos custos de produção é alto e sem um controle da propriedade o produtor pode chegar ao endividamento. São os fatores internos da produção leiteira, ou o "dentro da porteira", os quais possuem soluções e dependem dos produtores e de uma governança com propósito.

Em relação aos desafios externos, os entrevistados apontam que a carência de uma política pública consistente e de proteção aos produtores pode ocasionar o desestímulo, aliado à falta de sucessão familiar, ocorrendo a migração para as cidades. Além disso, as pequenas e médias propriedades sofrem com a concentração dos grandes produtores, perdendo forças na negociação, que em tempo de escala conseguem se manter.

A análise documental permitiu identificar outro desafio importante, que devido ao leite ser um commodity, há oscilação no preço, pois o mesmo é determinado pelo mercado e não existe um preço mínimo. Assim, deve-se ficar atento não somente ao mercado interno, mas ao externo também, que em virtude da sucessiva retirada das tarifas de importação, os produtos externos vão tomando espaço no mercado brasileiro e a concorrência torna-se global, atingindo diretamente o produtor. As influências de nível macro devem ser observadas quando se trata de cadeia de valor e a necessidade de uma governança com esta visão de mercado (KANO; TSANG; YEUNG, 2020).

Contudo, em que pese incipiente, existe a rede, importante elemento destacado por Kano, Tsang e Yeung (2020). A densidade das relações, a abertura e a imersão entre os agentes da cadeia produtiva, cada um contribuindo dentro da sua complexidade, podem fortalecer todo o ambiente. O mesmo servindo de exemplo para os produtores que necessitam colaborar mais uns com os outros e se unir entre eles para garantir a sobrevivência no mercado. A estruturação da rede dá certo quando várias entidades se juntam num processo coletivo, de crescimento e de qualificação que incentivem a produção do leite e que busquem os melhores meios para a redução de custos e a maximização de lucros. Portanto, verifica-se o potencial crescimento da cadeia produtiva do leite em torno da produção em conjuntos com os agentes da governança.

\section{CONSIDERAÇÕES FINAIS}

O objetivo desta investigação foi caracterizar e analisar a governança e a cadeia produtiva do leite na região do COREDE-RV. Para tanto, desenvolveu-se um caminho metodológico de análise de documentos, observação direta e entrevistas com agentes da cadeia produtiva. A análise dos dados coletados, permitiu identificar três categorias principais: coordenação, desafios e oportunidades.

Em relação a coordenação, os benefícios de se ter uma organização coletiva estruturada voltada para a produção de leite é principalmente a potencialização de pontos fortes e o trabalho para melhorar os pontos fracos da cadeia produtiva. Auxiliando assim, os produtores em suas dificuldades, principalmente nas pequenas e médias propriedades que estão mais necessitadas de apoio e incentivo, e contribuir inclusive para a sucessão familiar com garantia de sobrevivência.

A principal contribuição do estudo e que se relacionam com os desafios e oportunidades apontadas, é a caracterização da governança informal e híbrida existente na região estudada, ponto que deve ser considerado, pois indica que há coordenação, no entanto, carente de mecanismos de gestão, como planejamento, controle e avaliação. Uma ação que poderia potencializar a cadeia produtiva do leite na região, seria a formalização e a constituição de um Arranjo Produtivo Local (APL), com todo o seu referencial teórico e prático 
A governança da cadeia produtiva do leite:

um estudo de caso na região do Corede Rio da Várzea - RS

já presente em diferentes contextos. Por isso, concebe-se que é necessário um trabalho de conscientização dos agentes envolvidos, para vistas a importância da organização coletiva em torno a fortalecer-se como grupo e assim, potencializar todos os elos da cadeia.

Sendo o Brasil, um dos maiores produtores de leite do mundo, e, esse, somado aos seus derivados, torna-se uma parte considerável e importante na economia. Na região estudada, o COREDE-RV, que é predominantemente agrícola e pecuária, é necessário e imprescindível um olhar com vistas a seu grande potencial, ainda não explorado, como um todo. Já existindo um trabalho inicial de entidades em torno de intenções para ações objetivas à cadeia produtiva do leite, que busca justamente a conscientização do produtor na qualificação do produto. Acredita-se que o produtor organizado, com devido planejamento, investindo em sua propriedade e obtendo maiores conhecimentos do seu negócio, tem condições de melhorar e se manter no mercado competitivo.

Por fim, destaca-se que esta investigação é um dos resultados de projeto de pesquisa mais amplo que visa estruturar um APL na região do COREDE-RV, entendendo ser esta uma via de otimização de esforços, com vistas a mapear as influências macro e micro e institucionalizar uma governança formal em nível estrutural e estratégico, nos moldes do que apontam Kano, Tsang e Yeung (2020) em seu modelo conceitual, com vistas a atingir resultados mais promissores e inovadores.

\section{NOTA}

Artigo selecionado no fast track do VIII Simpósio da Ciência do Agronegócio na área de concentração de Cadeias produtivas, competitividade e inserção internacional, realizado de forma virtual, nos dias 05 e 06 de novembro de 2020.

\section{REFERÊNCIAS}

ARAÚJO, M. J. Fundamentos de Agronegócios. 2 ed. São Paulo: Atlas, 2007.

BARDIN, L. Análise de conteúdo. 5 ed. Lisboa: Edições 70, 2009.

BATALHA, M. O. (Coord.). GEPAI: Grupo de Estudos e Pesquisas Agroindustriais. 3. ed. São Paulo: Atlas, 2007.

BREITENBACH, R.; SOUZA, R. S. Caracterização de mercado e estrutura de governança na cadeia produtiva do leite na região noroeste do Rio Grande Do Sul. Organizações Rurais \& Agroindustriais, Lavras, v. 13, n. 1, p. 77-92, 2011.

BRUM, A. L. Mercado e cadeias produtivas. In: SIEDENBERG, D. (Org.). Desenvolvimento sob múltiplos olhares. Ijuí: UNIJUÍ, 2012.

CALLADO, A. A. C. Agronegócio. 3. ed. São Paulo: Atlas, 2010.

CANZIANI, J. Programa empreendedor rural: cadeias agroindustriais. Curitiba: Senar-PR, 2003.

DIAS, D. T. Á; DE TONI, D. Fatores impactantes no desempenho organizacional: proposição de um modelo conceitual. Revista Gestão Organizacional, v. 11, n. 3, 2018. 
EMBRAPA. Anuário Leite 2019. Disponível em: file://C:/Users/user/Downloads/AnuarioLEITE-2019.pdf. Acesso em: 10 jan. 2019.

EMBRAPA. Setor leiteiro pode sofrer menos que outros setores com a pandemia de Covid19. 2020. Disponível em: https://www.embrapa.br/busca-de-noticias//noticia/51459883/setor-leiteiro-pode-sofrer-menos-que-outros-setores-com-a-pandemiade-covid-19. Acesso em: 15 ago. 2020.

FENSTERSEIFER, J. E.; VIEIRA L. M. As opções estratégicas das empresas locais em face da globalização da atividade produtiva: um estudo exploratório na cadeia do leite.

Organizações Rurais \& Agroindustriais, v. 4, n. 2, p. 1-13, 2002. DOI:

http://dx.doi.org/10.22004/ag.econ.101915.

FUNDAÇÃO DE ECONOMIA E ESTATÍSTICA SIEGFRIED EMANUEL HEUSER. FEEDADOS. 2017. Disponível em: http://feedados.fee.tche.br/feedados/. Acesso em: 5 abr. 2019.

GODOY, A. S. Estudo de caso qualitativo. In: GODOI, C. K.; BANDEIRA-DE MELLO, R.; SILVA, A. B. (Org.). Pesquisa qualitativa em estudos organizacionais: paradigmas, estratégias e métodos. 2 ed. São Paulo: Saraiva, 2010.

GONZÁLEZ, R. S. Democracia participativa e conselhos de desenvolvimento. In.: BAQUERO, M.; CREMONESE, D. (Orgs.) Desenvolvimento regional, democracia local e capital social. Ijuí: Ed. Unijuí, 2008.

HUMPHREY, J.; SCHMITZ, H. Governance and upgrading in global value chains. Paper for the Bellagio Value Chain Workshop, Itália, August, 2000.

JUSTEN, G. S.; SOUZA, M. P. Estruturas de governança no arranjo produtivo local (APL) da castanha-da-amazônia no estado do Acre. Revista Brasileira de Gestão e Desenvolvimento Regional, v. 13, n. 3, 2017. DOI: http://dx.doi.org/10.5007/2175-8077.2017v19n47p114.

KANO, L.; TSANG, E. W.K.; YEUNG, H. W. Global value chains: A review of the multidisciplinary literature. Journal of International Business Studies, p. 1-46, 2020. DOI: https://doi.org/10.1057/s41267-020-00304-2.

KELM, M. S.; SAUSEN, J. O.; KELM, M. L. Posicionamento estratégico na cadeia produtiva do leite: análise das estratégias competitivas de uma cooperativa de produtores de leite. Organizações Rurais \& Agroindustriais, v. 17, n. 3, p. 369-382, 2015.

KISCHNER, P.; BRUM, A. L.; MUENCHEN, J. V.; BASSO, D.A. cadeia produtiva do leite na Região Noroeste do RS: estudo de caso do município de ljuí. Brazilian Journal of Development, v. 5, n. 9, p. 15162-15176, 2019.

LAVILLE, C.; DIONNE, J. A construção do saber: manual de metodologia de pesquisa em ciências humanas. Belo Horizonte (MG): UFMG, 1999. 
A governança da cadeia produtiva do leite:

um estudo de caso na região do Corede Rio da Várzea - RS

MAPA. Ministério da Agricultura, Pecuária e Abastecimento. China abre mercado para lácteos brasileiros. 2019. Disponível em: http://www.agricultura.gov.br/noticias/china-abremercado-para-lacteos-brasileiros. Acesso em: 14 set. 2019.

MEDEIROS, F. M.; BRUM, A. L. O mercado do leite no Rio Grande do Sul: evolução e tendências. 2016. 24 p. MBA em Finanças e Mercado de Capitais. Unijui - Universidade Regional do Noroeste do Estado do Rio Grande do Sul. Disponível em: https://bit.ly/3ieBLOp. Acesso em: 20 jul. 2020.

OMS - ORGANIZACIÓN MUNDIAL DE LA SALUD. Brote de enfermedad por coronavirus (COVID-19). Disponível em: https://www.who.int/es/emergencies/diseases/novelcoronavirus-2019. Acesso em: 14 set. 2020.

PETTIGREW, A. M. Contextualist research: a natural way to link theory and practice. In: LAWLER III, E. E. Doing research that is useful in theory and practice. San Francisco: JosseyBass, 1985.

REIS, J. G. M.; COSTA NETO, P. L. O. Engenharia de produção aplicada ao agronegócio. Edgard Blücher, 2018.

SUZIGAN, W.; GARCIA, R.; FURTADO, J. Estruturas de governança em arranjos ou sistemas locais de produção. Gestão \& Produção, v. 14, n. 2, 425-439, 2007. DOI:

http://dx.doi.org/10.1590/S0104-530X2007000200017.

TELLES, T. S.; BACCHI, M. D.; COSTA, G. V.; SCHUNTZEMBERGER, A. Milk production systems in Southern Brazil. Anais da Academia Brasileira de Ciências, v. 92, n. 1, 2020. DOI: https://doi.org/10.1590/0001-3765202020180852.

UNITED NATIONS DEPARTMENT OF ECONOMIC AND SOCIAL AFFAIRS. World Population Prospects The 2017 Revision. 2017.

VIANA, G.; FERRAS, R. P. R. A cadeia produtiva do leite: um estudo sobre a organização da cadeia e sua importância para o desenvolvimento regional. Revista Capital Científico, v. 5, n. $1,2007$.

VIANA, G.; RINALDI, R. N. Principais fatores que influenciam o desempenho da cadeia produtiva de leite - um estudo com os produtores de leite do município de Laranjeiras do Sul - PR. Organizações Rurais \& Agroindustriais, v. 12, n. 2, p. 263-274, 2010.

ZYLBERSZTAJN, D.; NEVES, M. F. Economia \& Gestão dos Negócios Agroalimentares. São Paulo: Pioneira, 2000.

ZYLBERSZTAJN, D.; NEVES M. F.; CALEMAN, S. M. Q. Gestão de Sistemas de Agronegócios. 1 ed. São Paulo: Atlas, 2015. 